2 Wickramasinghe, N. C. Narure 252, 462 (1974).

Wickramasinghe, N. C. Mon. Not. R. usir. Soc. 170, P11 (1975)

Mendis, D. A. \& Wickramasinghe, N. C. Astrophys. Space Sci. 37, L_13 (1975)

Cooke, A. \& Wickramasinghe, N. C. Astrophl's. Space Sci. (in the press).

Hoyle F, \& Wickramasinghe, N. C. N'ature 264. 45 (1976).

Organic Electronic Spectral Data, 1-5 (Interscience, New York, 1946-1961).

Wirkrolet Reference Spectra (Sadtler Research 1,aboratories, Philadelphia).

ckramasinghe N. C. Hoyle, F. \& Nandy, K. Astrophys. Space Sci. (in the press).

Bless R. C \& Savage, B. D. A trophys. J 171, 293 (1972)

Nandy, K., Thompson, G. I., Jamar, C., Monfils, A. \& Wilson, R. Astr. Astrophys 44, 195(1975).

Cronin, J. R. \& Moore, C. B. Geochin. cosmochin. Acta 40, 853 (1976)

Breger, I. A., Zubovic, P., Chandler, J. C. \& Clarke, R. S. Nature 236, 155 (1972).

Cairns-Smith, A. G.J. theor. Biol. 10,53 (1965).

\section{Gravitational radiation detector observations in 1973 and 1974}

MARYLAND-ARGONNE gravitational radiation detector observations for 1973-74 have recently been published ${ }^{1}$. This letter contains additional information about how the data were taken and analysed.

A primary goal was to eliminate any unconsciously applied human bias which could affect results. To this end, I removed myself from direct participation in the data reduction beginning in 1972. Mr Michael Lee developed programs for a magnetic tape and computer system of data analysis. A number of checks of the computing were set up. The first check was an independent, analogue experiment, in which data were recorded on pen-and-ink charts, with an on-line computer marking the charts whenever the Maryland and Argonne detectors both crossed threshold within $0.1 \mathrm{~s}$. The pen-and-ink recorder experiment had two outputs, one with, and one without, a time delay introduced into one of the channels before the computer looked for simultaneous threshold crossings. Charts for the data with and without the time delay were marked in coded form (which changed from time to time). Mrs Alessandra Exposito searched the charts for statistically significant coincidences without knowing which charts were which. This analogue procedure found excess coincidences at zero time delay during the same periods that the computerised experiment found them.

In a second checking procedure, Mr William Davis inserted artificial pulses into the gravitational radiation detectors at certain times unknown to the programmer, Mr Michael Lee. Lee correctly identified times when artificial pulses were present and absent. Third, Mr Bruce Webster prepared copies of old data tapes, some identical with the originals and others with one or more channels replaced by the same detector data from another time period. Lee had no knowledge of the information recorded on the magnetic tapes. Lee's analysis correctly identified these tapes.

The telephone circuit from the Argonne detector to Maryland was suspect even though the data were transmitted in coded digital form. The recent paper includes all data for a period when there was no telephone circuit and clock-synchronised recorders were employed at the two detector sites. An excess of coincidences over accidentals was observed during that period.

A major effort has been made to eliminate computing errors. Maryland magnetic tape data were sent to several other research groups together with data on the computer programs and lists of coincidences, in return for raw data from their experiments. During the data exchange, errors were discovered in the Maryland programs and in the procedures of other groups. The Maryland errors were acknowledged quickly and carefully corrected. The differences have now been resolved, and independent groups have confirmed the details of the revised Maryland programming. At the request of two research groups, the data exchange was to be private until agreement could be reached on publication. It is regrettable that incorrect and premature reports on the data exchange have appeared in the literature.

Two of the four authors of ref. 1, Steppel and Lee, independently prepared computer programs to process these data.
In summary, results of the magnetic tape computer experiment, the pen-and-ink recorder experiment, and the data exchange indicate that for certain periods there is an excess of coincidences over accidental ones, with significance as great as $5.6 \mathrm{~s}$.d. The use of several independent programs and of the checks in which the searcher did not know what was on the tapes or charts indicates that human observer bias and programming errors have been successfully removed.

This research was supported in part by the National Science Foundation and in part by the Computer Science Center, University of Maryland.

\section{J. WEBER}

University of Maryland, College Park, Maryland 20742 and University of California, Irvine, California 92717

Received 5 October 1976; accepted 19 January 1977.

1 Lee, M. et al. Phys. Rev. D14(4), 893 (1976).

\section{Radiometric measurement of stratospheric $\mathbf{H C l}$}

INTEREST in the effects on atmospheric ozone of man-made chlorine compounds has prompted research into their stratospheric chemistry. As $\mathrm{HCl}$ is expected to be the major temporary sink for free chlorine in the stratosphere ${ }^{1-4}$, measurements of its vertical mixing ratio profile could yield useful information as to the major source of chlorine and its future effects on ozone concentrations. We have used a balloon-borne pressure modulator radiometer (PMR) to measure the atmospheric absorption of solar infrared radiation at sunset, and we report here a vertical mixing ratio profile for gaseous $\mathrm{HCl}$ for the altitude range $16-39 \mathrm{~km}$.

The major feature of the PMR is a cell containing gas $(\mathrm{HCl}$, in this case) through which the incoming radiation passes ${ }^{5}$. The gas pressure is modulated at about $19 \mathrm{~Hz}$ and the mean pressure in the cell chosen to give maximum modulation of cell transmission at $\mathrm{HCl}$ spectral line centres. Thus the incoming radiation is selectively modulated in those narrow spectral regions where atmospheric $\mathrm{HCl}$ absorbs, and so the pressure modulator cell acts as a filter of very high resolution $\left(\sim 4 \times 10^{-3} \mathrm{~cm}^{-1}\right)$.

The front optics of the radiometer is a servocontrolled Sun tracking system built by Denver University ${ }^{6}$, which maintains an image of the Sun at the detector. The optical system also contains a rotating chopper which modulates the incoming radiation at $400 \mathrm{~Hz}$ and an optical filter which defines a pass band about $300 \mathrm{~cm}^{1}$ wide around $2850 \mathrm{~cm}^{-1}$. This region of the spectrum contains most of the fundamental vibration rotation band of $\mathrm{HCl}$. The detector, made of lead selenide at ambient temperature, receives radiation which has components at $400 \mathrm{~Hz}$ (the wide-band signal), at $19 \mathrm{~Hz}$ (the PMR signal) and at $400 \pm 19 \mathrm{~Hz}$ (the sideband signal). The PMR and side-band signals contain the same information but the latter is used for instrumental convenience. The side-band:wide-band ratio is related to the amount of atmospheric $\mathrm{HCl}$ in the path between the instrument and the Sun.

The results presented here were obtained on a flight from Holloman USAF base, New Mexico $\left(32^{\prime} 52^{\prime} \mathrm{N}, 106^{\prime}\left(7^{\prime} \mathrm{W}\right)\right.$ on 17 March 1976. The radiometer remained at its float altitude of about $35.5 \mathrm{~km}$ until after sunset and was able to take measurements for solar zenith angles $\geq 90^{\circ}$. In this way the Sun is viewed through a long atmospheric path, enabling low concentrations of trace constituents to be detected. This technique (limb scanning) also allows vertical resolution in mixing ratio profile to be obtained. Signals for zenith angles $<90$ are used to calculate the level of the level of the side-band:wide-band ratio when there is no atmospheric absorption.

The mixing ratio profile has been derived from the data using a computer model which calculates the signals expected from a PMR for a given atmosphere by performing a line by line numerical integration across a Voigt profile for all the $\mathrm{HCl}$ spectral lines in the pass band of the filter. The spectral line strengths and Lorentz halfwidths used are those given by Tothe $\mathrm{al}^{7,8}$. The results are shown in Fig. 1. Relative errors are indicated; also, at the present stage of analysis, there may be an absolute error of up to $\pm 20 \%$ in the 